\title{
LEPTIN STIMULATES PHOSPHOINOSITIDE 3-KINASE IN THE VASCULAR WALL: ROLE OF ERBB RECEPTORS
}

\author{
Jerzy Bełtowski*, Grażyna Wójcicka, and Sylwia Widomska \\ Department of Pathophysiology, Medical University, Lublin, Poland
}

\begin{abstract}
Phosphoinositide 3-kinase (PI3K) phosphorylates phosphatidylinositol 4,5-diphosphate to phosphatidylinositol 3,4,5-triphosphate which then activates multiple intracellular signaling proteins such as protein kinase B (Akt), glycogen synthase kinase-3 3 , mammalian target of rapamycin (mTOR), etc. PI3K is involved in the regulation of vascular smooth muscle cell contractility, migration and proliferation - processes crucial for the pathogenesis of hypertension, atherosclerosis and restenosis. Increased leptin concentration in the metabolic syndrome contributes to the pathogenesis of cardiovascular diseases, but the effect of leptin on vascular smooth muscle cells is controversial. We examined the effect of experimentally induced hyperleptinemia on PI3K activity in the rat aortic media in adult male Wistar rats. Leptin, administered for 10 days in increasing dose (from 0.05 to $0.25 \mathrm{mg} / \mathrm{kg}$ every 12 hours), increased PI3K activity in the aortic media about 5 -fold. The effect of leptin was markedly attenuated by epidermal growth factor receptor (EGFR) inhibitor, AG1478, as well as by the ErbB2 receptor inhibitor, AG825. In addition, leptin increased tyrosine phosphorylation of ErbB2, which was abolished by either AG1478 or AG825. These results indicate that hyperleptinemia increases the activity of vascular ErbB2 receptor in EGFR-dependent manner. In addition, both EGFR and ErbB2 contribute to PI3K stimulation by leptin. Activation of ErbB2 and $\mathrm{PI3K}$ may contribute to detrimental effects of leptin on vascular contractility and remodeling and may be involved, at least in part, in the relationship between metabolic syndrome and increased risk of vascular restenosis after angioplasty.
\end{abstract}

Adipobiology 2011;3:53-59

Key words: obesity, phosphoinositide 3-kinase, vascular smooth muscle cells, arterial hypertension, atherosclerosis, restenosis

Received 14 December 2011, accepted 23 December 2011.

* Correspondence: Dr Jerzy Bełtowski, Department of Pathophysiology, Medical University, ul. Jaczewskiego 8, PL-20-090 Lublin,

Poland. Tel.: +48 81 7187365; Fax: +48 81 7187364; E-mail: jerzy.beltowski@umlub.pl; jerzybel@hotmail.com

\section{Introduction}

Phosphoinositide 3-kinases (PI3K) constitute the family of lipid kinases which phosphorylate hydroxyl group at the $3^{\text {rd }}$ position of inositol ring in plasma membrane phosphatidylinositol 4,5-diphosphate $\left(\mathrm{PIP}_{2}\right)$ converting it phosphatidylinositol 3,4,5-triphosphate $\left(\mathrm{PIP}_{3}\right)$. $\mathrm{PIP}_{3}$ regulates the activity of multiple proteins by binding to their pleckstrin homology $(\mathrm{PH})$ domains leading to activation of downstream signaling pathway such as phosphoinositide-dependent protein kinase-1 (PDK-1), protein kinase B (Akt), mammalian target of rapamycin (mTOR), glycogen synthase kinase-3 $\beta$ (GSK-3 $\beta$ ) and ribosomal protein S6 kinase (S6K). PI3K-dependent signaling is involved in the regulation of many physiological processes including insulin-induced glucose uptake, cell growth, proliferation and survival (1). In the vascular system, PI3K mediates stimulation of endothelial NO synthase (eNOS) in endothelial cells by various factors such as insulin, estrogens and fluid shear stress, whereas in vascular smooth muscle cells it is involved in the regulation of cell growth, migration, proliferation, 
and switch between contractile and synthetic/secretory phenotypes (2). The best characterized class IA PI3Ks are activated by growth factor receptors such as epidermal, platelet-derived and insulin-like growth factor-1 receptors (EGFR, PDGFR and IGF$1 \mathrm{R})$. Among them, EGFR is most abundant in the vascular wall and is activated therein not only by its multiple ligands but also in ligand-independent manner by various mediators such as angiotensin II, endothelin 1, thrombin, bradykinin and aldosterone (3). Increased EGFR activity contributes to abnormal vasoconstriction, blood pressure elevation and vascular remodeling in various experimental models of hypertension.

Leptin is produced in adipose tissue and regulates energy balance by acting on hypothalamic satiety and autonomic centers. Plasma leptin concentration is markedly increased in obese subjects. Many experimental and clinical studies suggest that hyperleptinemia is involved in the pathogenesis of cardiovascular complications of obesity including arterial hypertension and atherosclerosis (4). Previously, we (5) and others (6) have demonstrated that experimentally induced hyperleptinemia activates EGFR in the vascular wall in ligand-independent manner; the phenomenon referred to as transactivation. In addition, EGFR activated by leptin stimulates downstream extracellular signal-regulated kinases (ERK). Apart from ERK, PI3K is the second most important signaling pathway triggered by EGFR. Although leptin has been demonstrated to stimulate PI3K in various tissues (7), its effect on PI3K in the vascular wall has not been studied. Although some effects of leptin on vascular cells were attenuated by PI3K inhibitors such as wortmannin or LY294002, these inhibitors have also PI3K-independent effects and thus their effectiveness is not a definite evidence of the involvement of this pathway. Taking into account prominent role of PI3K in vascular homeostasis, in the present study we examined the effect of experimental hyperleptinemia on PI3K activity in the vascular wall using a recently developed AlphaScreen assay. The results indicate that leptin activates PI3K through the mechanism involving EGFR and its heterodimeric partner, ErbB2 receptor.

\section{Materials and methods Experimental model}

The study was performed on adult male Wistar rats weighing $237 \pm 8 \mathrm{~g}$ before the experiment. After 2-week acclimation, animals were randomized to three experimental groups: (1) control, (2) leptin-treated, (3) pair-fed, in which the amount of food served was restricted to match food intake in leptin-treated group (leptin administration decreased food intake by $15-20 \%$ in this model). Leptin was administered for 10 days in increasing doses from 0.05 to $0.25 \mathrm{mg} / \mathrm{kg}$ s.c. twice daily (between 7.00 and 8.00 AM and between 7.00 and 8.00 PM) to reproduce progressive increase in plasma leptin observed in the metabolic syndrome. The details of the procedure were described previously (5). Groups not receiving leptin were injected with the equal volume of saline. Separate groups of rats received leptin or saline plus one of growth factor receptor inhibitors (each once daily i.p. in $0.2 \mathrm{ml}$ of $20 \% \mathrm{DMSO}$ in $0.9 \% \mathrm{NaCl}$ ): AG1478 (EGFR inhibitor), AG43 (EGFR-inactive analogue of AG1478), AG825 (ErbB2 inhibitor), AG1295 (PDGFR inhibitor) or AG1024 (IGF$1 \mathrm{R}$ inhibitor). AG825 was administered at $100 \mathrm{mg} / \mathrm{kg} /$ day and all other inhibitors at $20 \mathrm{mg} / \mathrm{kg} /$ day.

Animals were anesthetized with thiopental (50 mg/kg i.p.) 6 hours after the last injection and blood was withdrawn from the abdominal aorta into EDTA-containing tubes to measure plasma leptin, insulin, glucose and lipids. Then, thoracic and abdominal aorta was excised, adventitia and perivascular adipose tissue were dissected and endothelium was removed by a cotton wool. Aortic media was frozen in liquid $\mathrm{N}_{2}$ and stored at $-80^{\circ} \mathrm{C}$ until analysis.

\section{PI3K assay}

PI3K activity was measured by a recently developed Alpha Screen method (ㅅmplified luminescence proximity homogeneous assay). In brief, the method is based on the chain interaction between donor microbeds coated with streptaividin, biotinylated $\mathrm{PI}(1,3,4,5) \mathrm{P}_{4}$, phosphoinositide detector protein (PH domain of mouse general receptor for phosphoinositides, GRPI) tagged with glutathione S-transferase (GST), and acceptor microbeds coated with anti-GST antibody. When this interaction occurs, donor microbeds excited with laser light $(680 \mathrm{~nm})$ produce singlet oxygen $\left({ }^{1} \mathrm{O}_{2}\right)$ which induces luminescence (520-620 nm) in the acceptor beds; the emitted light is then detected. $\mathrm{PIP}_{3}$ standard or $\mathrm{PIP}_{3}$ produced by $\mathrm{PI} 3 \mathrm{~K}$ contained in the sample competes with biotinylated PIP for binding with GRPI and "breaks" the chain interaction between donor and acceptor beds; due to short half-life of singlet oxygen $(4 \mu \mathrm{s})$ it spontaneously returns to basal low-energy state before reaching acceptor beds and luminescence signal is not emitted. Thus, signal intensity decreases with increasing PIP $_{3}$ concentration in the sample.

The assay was performed using PI3K assay kit purchased from Echelon Bioscience Technology (Salt Lake City, USA), suspension of donor and acceptor microbeds was obtained from Perkin Elmer GST Alpha Screen Assay kit. Thawed tissue samples were homogenized in 10 volumes of $20 \mathrm{mM}$ Tris $(\mathrm{pH}$ 7.5) containing $150 \mathrm{mM} \mathrm{NaCl}, 1 \mathrm{mM}$ EDTA, $1 \mathrm{mM}$ EGTA, 1\% Triton X-100, $2.5 \mathrm{mM}$ sodium pyrophosphate, $1 \mathrm{mM} \mathrm{Na} \mathrm{VO}_{4}$, $1 \mu \mathrm{g} / \mathrm{ml}$ leupeptin and $1 \mathrm{mM}$ phenylmethylsulphone fluoride, 
and centrifuged at $15000 \times \mathrm{g}$ for $10 \mathrm{~min}$ at $4^{\circ} \mathrm{C}$. The reaction mixture $(10 \mu \mathrm{l})$ contained $5 \mu \mathrm{g}$ of tissue supernatant protein, $10 \mu \mathrm{M}$ ATP, $5 \mu \mathrm{M}$ substrate (dioctanoyl-PI $(4,5) \mathrm{P}_{2}$ ) and $2.5 \mathrm{mM}$ $\mathrm{MgCl}_{2}$ in $5 \mathrm{mM} \mathrm{HEPES} \mathrm{(pH} \mathrm{7.4).} \mathrm{After} 2$ hours at $37^{\circ} \mathrm{C}, 5 \mu \mathrm{l}$ of $50 \mathrm{nM}$ biotinylated $\mathrm{PIP}_{4}, 5 \mu \mathrm{l}$ of $1.85 \mu \mathrm{g} / \mathrm{ml}$ detector protein (both in $10 \mathrm{mM}$ Tris containing $150 \mathrm{mM} \mathrm{NaCl}, 7.5 \mathrm{mM}$ EDTA, $0.1 \%$ Tween-20 and $1 \mathrm{mM}$ dithiotreitol, $\mathrm{pH}$ 7.4) and $5 \mu \mathrm{l}$ of suspended donor and acceptor microbeds $(100 \mu \mathrm{g} / \mathrm{ml}$ each) were added to the wells and the plate was incubated for additional 2 hours at room temperature. The signal was read using PherAstar FS (BMG Labtech) microplate reader in the Alpha Screen mode (excitation $300 \mathrm{~ms}$, emission $700 \mathrm{~ms}$ ). Standard curve was obtained by adding $10 \mu \mathrm{l}$ of $0-2,5 \mu \mathrm{M}$ dioctanoyl$\mathrm{PIP}_{3}$ instead of reaction mixture, followed by biotinylated PIP detector protein and microbeds as described above. PI3K activity is expressed in pmol of $\mathrm{PIP}_{3}$ produced per mg of supernatant protein per hour.

\section{Phosphorylation of ErbB2 receptor}

The activity of ErbB2 receptor was assessed by measuring its phosphorylation at $\mathrm{Tyr}^{1221}$ and/or $\mathrm{Tyr}^{1222}$ (the major autophosphorylation sites for ErbB2 tyrosine kinase and PI3K docking site) and global phosphorylation (phosphotyrosine residues regardless of position in the aminoacid chain). These assays were performed by ELISA method using kits from Cell Signaling Technology. Total ErbB2 level was also measured. In brief, 100 $\mu \mathrm{l}$ of tissue supernatant used for PI3K assay (diluted to $0.1 \mathrm{mg}$ protein $/ \mathrm{ml}$ ) was pipetted to the microplate wells coated with anti-ErbB2 antibody. After 2-hour incubation and washing, 100 $\mu \mathrm{l}$ of secondary antibody solution specific for ErbB2 regardless of its phosphorylation state (total ErbB2), ErbB2 phosphorylated at $\mathrm{Tyr}^{1221}$ and/or $\mathrm{Tyr}^{1222}$, or anti-phosphotyrosine antibodies was added. After 1-hour incubation and washing, horseradish-peroxidase-linked antibodies specific for Fc fragment of the respective secondary antibodies were added together with $\mathrm{H}_{2} \mathrm{O}_{2}+$ trimethylbenzidine substrate. The results are expressed as the ratio between optical density (OD) measured at $450 \mathrm{~nm}$ for phosphorylated and total ErbB2.

\section{Reagents}

Recombinant rat leptin was purchased from R\&D Systems. AG825 was from Sigma-Aldrich and all other receptor tyrosine kinase inhibitors were from Calbiochem.

\section{Statistical analysis}

Results are expressed as mean \pm SEM from 8 experiments in each group. Statistical significance was evaluated by ANOVA and Tukey's post-hoc test. $\mathrm{P}<0.05$ was considered significant.

\section{Results}

Characteristics of experimental groups

Final body weight, plasma glucose, triglycerides, total and HDLcholesterol did not differ between groups. Leptin concentration was markedly higher in leptin-treated group, but was reduced by $>40 \%$ in the pair-fed group in comparison to control. Leptin administration had no effect on plasma insulin concentration, whereas pair-feeding induced slight decrease in fasting plasma insulin suggesting improvement of insulin sensitivity (Tab. 1).

\section{PI3K activity}

Leptin administration resulted in about 5-fold elevation of PI3K activity in the aortic media. In contrast, pair-feeding had no effect on PI3K activity (Fig. 1). These results indicate that leptin excess but not caloric restriction is responsible for PI3K activation in leptin-treated group.

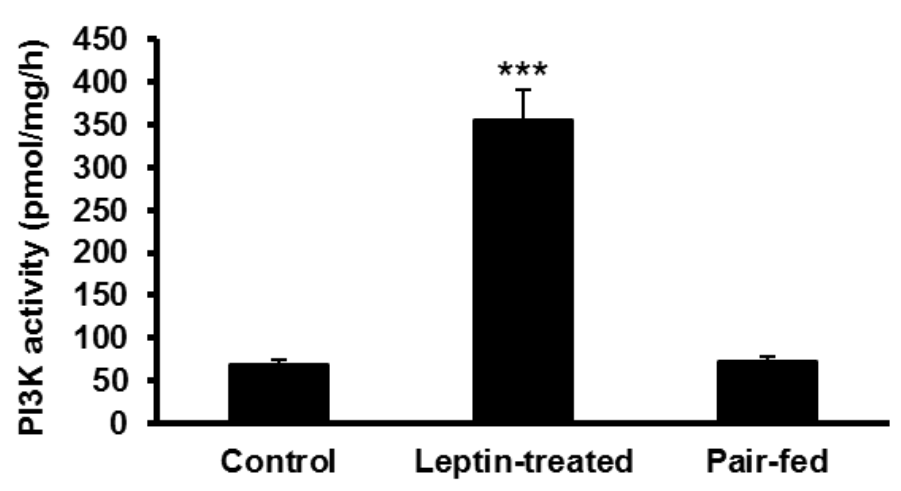

Figure 1. Phosphoinsitide 3-kinase (PI3K) activity in the aortic media (pmol/mg protein/hour). ${ }^{* *} \mathrm{p}<0.001$ versus control group.

Effect of growth factor receptor inhibitors on leptin-induced PI3K activation

Because PI3K is activated by growth factor receptors, in subsequent studies we examined if and which of these receptors are involved in leptin-induced PI3K stimulation. Both AG1478 and AG825 reduced this activity in leptin-treated animals, however, neither of them completely restored PI3K activity to control level. AG1295 reduced PI3K activity in leptin-treated group to a much lesser extent (-22.2\%). An inactive analogue of AG1478, AG43, as well as IGF-1R inhibitor, AG1024, had no effect. Neither of tyrphostins had any effect on PI3K in rats not receiving leptin (Fig. 2). These results indicate that EGFR and ErbB2 are mostly involved in leptin-induced stimulation of PI3K. 


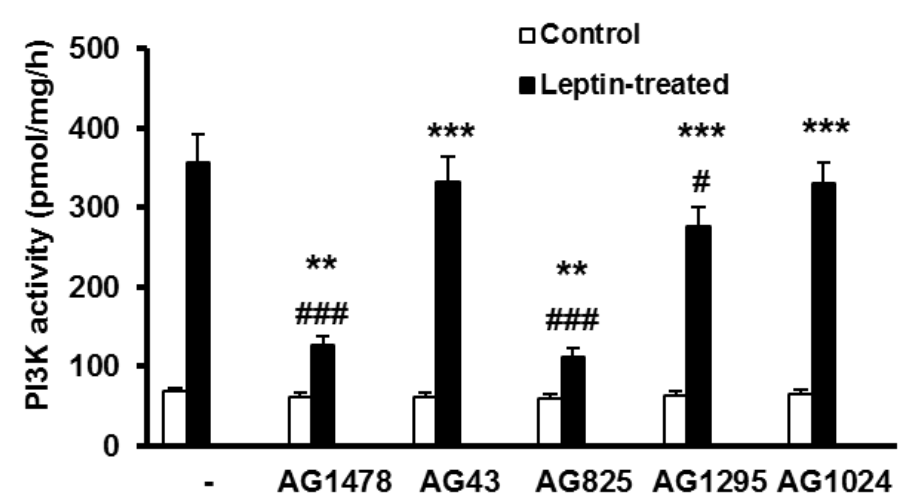

Figure 2. Effect of growth factor receptor inhibitors on leptin-induced PI3K stimulation in the aortic media. ${ }^{* *} \mathrm{p}<0.01,{ }^{* * *} \mathrm{p}<0.001$ versus control group; ${ }^{\# \# \#} \mathrm{p}<0.001$ versus group receiving leptin alone.

\section{ErbB2 phosphorylation}

Neither leptin nor any of growth factor receptor inhibitors had any significant effect on total ErbB2 concentration in the aortic wall (not shown). ErbB2 phosphorylation at $\mathrm{Tyr}^{1221} / \mathrm{Tyr}^{1222}$ was 3-fold higher in leptin-treated that in control animals. Both AG1478 and AG825 restored ErbB2 phosphorylation at Tyr ${ }^{1221 /}$ $\mathrm{Tyr}^{1222}$ to the control level, whereas AG1295, AG1024 and AG43 had no effect. Interestingly, AG1478 and AG825 slightly reduced ErbB2 phosphorylation (by $40.7 \%$ and $27.0 \%$, respectively) in animals not receiving leptin (Fig. 3A).

Leptin induced also marked increase in global ErbB2 phosphorylation (total amount of phosphotyrosine residues). This effect was partially attenuated but not completely normalized by either AG1478 or AG825. AG43, AG1295 and AG1024 had no effect on global ErbB2 phosphorylation in leptin-treated animals. AG1478 reduced global ErbB2 phosphorylation in anmimals not receiving leptin by $46.2 \%$, whereas other inhibitors had no effect in this group (Fig. 3B).

\section{Discussion}

The major finding of this study is that experimental hyperleptinemia induced in lean rats stimulates PI3K in the aortic media in which vascular smooth muscle cells constitute the main cellular component. Hyperleptinemia induced in lean animals by administration of exogenous hormone is a good model to dissect effects of leptin excess from other endocrine/metabolic abnormalities observed in the metabolic syndrome, and thus to recognize which detrimental consequences of obesity may be
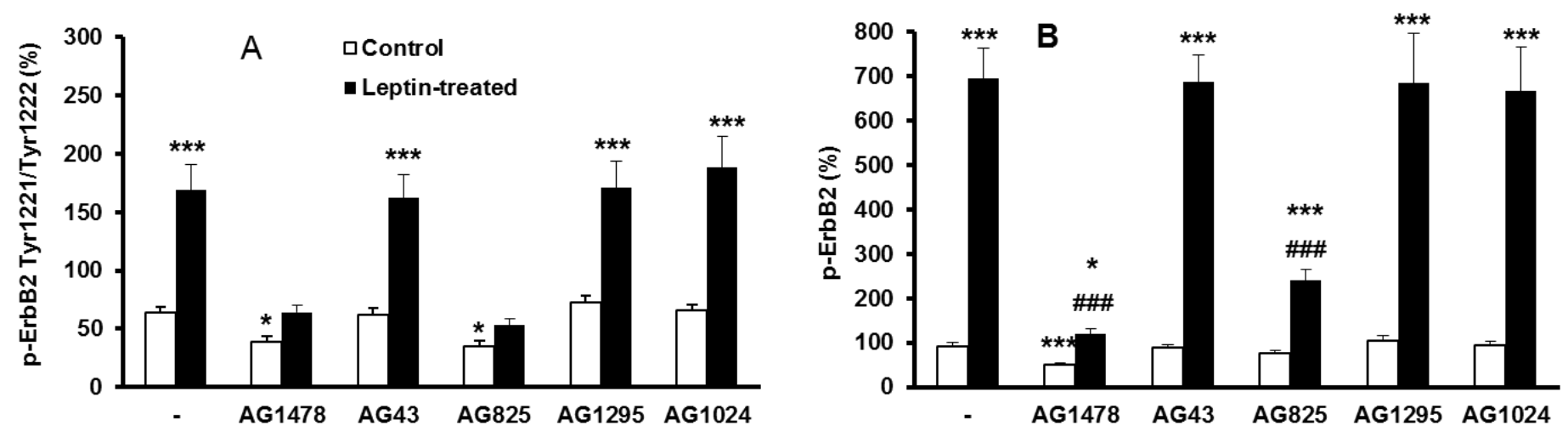

Figure 3. Phosphorylation of ErbB2 at $\operatorname{Tyr}^{1221} / \operatorname{Tyr}^{1222}(\mathbf{A})$ and global phosphorylation of ErbB2 (the amount of all phosphotyrosine residues, B) in rats receiving leptin and/or growth factor receptor inhibitors. Results are expressed as the ratio between optical density measured using antibodies specific for phosphorylated ErbB2 and total ErbB2. ${ }^{*} p<0.05,{ }^{* * *} p<0.001$ versus control group;

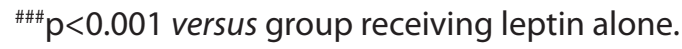


attributed to hyperleptinemia. Although conditions used during PI3K assay such as substrate and ATP concentration, buffer composition, etc, are optimal for class IA PI3Ks which are activated by growth factor receptors, we cannot definitely conclude which specific PI3K isoform is activated. Previously, we have demonstrated that hyperleptinemia increases EGFR activity in the vascular wall by inducing reactive oxygen species-mediated stimulation of non-receptor tyrosine kinase c-Src which phosphorylates the intracellular domain of EGFR (5). In addition, leptin increased ERK activity in EGFR-dependent but IGF-1R and PDGFR-independent manner $(5,6)$. Consistently with these findings, leptin-induced PI3K stimulation in the present study was markedly attenuated by EGFR inhibitor, AG1478. Surprisingly, the effect of leptin on PI3K was also markedly reversed by ErbB2 inhibitor, AG825. Among all ErbB receptors (EGFR/ErbB1 through ErbB4), ErbB2 has no specific ligand but may heterodimerize with and be phosphorylated by other ErbB family members including EGFR. Indeed, ErbB2 is a preferred dimerization partner for other ErbB receptors; binding with ErbB2 increases ligand affinity of EGFR, augments its ability to stimulate downstream signaling, and prolongs EGFR activation by slowing its endocytosis $(3,8,9)$. Thus the most likely explanation of our findings is that EGFR, activated by leptin, phosphorylates and activates ErbB2 which finally recruits the regulatory subunit of PI3K leading to its stimulation. Indeed, we demonstrated that leptin increased ErbB2 phosphorylation in the aortic wall while having no effect on total ErbB2 level, and that its effect on ErbB2 phosphorylation was abolished by AG1478 (Fig. 3), as well as by either antioxidant apocynin or c-Src inhibitor PP2 (data not shown), which also abolish the effect of leptin on EGFR (5).

Overexpression or constitutive activation of ErbB2 is observed in many cases of human cancer. Previously, leptin has been demonstrated to activate ErbB2 in two breast cancer cell lines (10) and in human embryonic kidney HEK293T cells transfected with ErbB2 (11). In addition, similarly to the present study, in SKBR3 breast cancer cells the effect of leptin on ErbB2 phosphorylation was partially attenuated by AG1478 suggesting the involvement of EGFR (10). Leptin-induced ERK activation and proliferation of breast cancer cells were attenuated by AG825 indicating that ErbB2, stimulated by leptin, is able to activate downstream signaling mechanisms. To our knowledge, the present study is the first one in which the effect of leptin on ErbB2 phosphorylation was demonstrated in nonmalignant tissues.

ErbB2 is expressed in vascular smooth muscle cells but, in contrast to EGFR, its role in these cells is poorly understood. It has been demonstrated that EGFR/ErbB1 agonist, betacellulin, is synthesized by rat aortic smooth muscle cells and stimulates phosphorylation of both EGFR and ErbB2; phosphorylation of the latter was abolished by EGFR inhibitors confirming that both receptors may dimerize in vascular smooth muscle cells and that ErbB2 is phosphorylated by liganded EGFR (12). In addition, betacellulin stimulated smooth muscle cell growth, migration and proliferation in EGFR, ErbB2, and partially PI3Kdependent manner (12). Other EGFR ligands such as heparinbinding EGF-like growth factor, epiregulin and amphiregulin are also synthesized in vascular smooth muscle cells and regulate their growth and proliferation. Angiotenisn II, thrombin and endothelin-1 stimulate synthesis of these ligands and also transactivate EGFR in ligand-independent manner (3). Taken together, these data indicate that EGFR, either activated by its ligands or stimulated in ligand-independent (e.g. transactivated by leptin) manner, can phosphorylate ErbB2 and trigger downstream signaling pathways including PI3K in vascular smooth muscle cells. It should be noted that once phosphorylated, intracellular domain of ErbB2 recruits and activates some signaling proteins with greater affinity than EGFR, and specific signaling proteins such as FGR, Abl-1 and Syk cytosolic protein tyrosine kinases are activated exclusively by ErbB2 but not by EGFR (13). The role of ErbB2 in vascular smooth muscle cells needs to be studied in more detail in the future.

Functional implications of leptin-induced PI3K stimulation in the vascular wall remain to be established. In contrast to endothelial cells where PI3K activates eNOS, PI3K in vascular smooth muscle cells is rather involved in vasoconstriction. Indeed, PI3K is activated by angiotensin II or endothelin-1 and mediates vasoconstriction by increasing intracellular $\mathrm{Ca}^{2+}$ concentration and/or the sensitivity of intracellular contractile apparatus to $\mathrm{Ca}^{2+}$ (14-18). Increased expression/activity of PI3K was observed in experimental models of hypertension $(19,20)$. In addition, genetic or pharmacological PI3K inhibiton reduce blood pressure in experimental animals $(21,22)$. Hyperleptinemia is involved in the pathogenesis of hypertension in patients with metabolic syndrome (4), thus leptin-induced PI3K stimulation in the vascular wall may also contribute to vasoconstriction. In addition, PI3K and its downstream effectors such as Akt, mTOR and S6K are involved in vascular smooth muscle cell growth, migration and proliferation; processes crucial for progression of atherosclerosis and restenosis after coronary angioplasty (23-25). Administration of exogenous leptin augments, whereas deficiency of leptin or its receptor attenuates experimental restenosis induced by vascular injury in rodents (26-28), and hyperleptinemia correlates with increased risk of restenosis in humans (29-30). However, detrimental effect of leptin in the vascular wall is not unequivocal since leptin has 
Table 1. Characteristics of experimental groups

\begin{tabular}{|l|l|l|l|}
\hline Group & Control & Leptin-treated & Pair-fed \\
\hline Body weight $(\mathrm{g})$ & $307 \pm 7$ & $286 \pm 9$ & $289 \pm 8$ \\
\hline Plasma leptin $(\mathrm{ng} / \mathrm{ml})$ & $3,7 \pm 0,4$ & $14,2 \pm 1,8^{* * *}$ & $2,1 \pm 0,3^{* *}$ \\
\hline Plasma insulin $(\mathrm{ng} / \mathrm{ml})$ & $2,23 \pm 0,28$ & $1,85 \pm 0,17$ & $1,78 \pm 0,16^{*}$ \\
\hline Plasma glucose $(\mathrm{mM})$ & $5,87 \pm 0,11$ & $5,73 \pm 0,16$ & $5,66 \pm 0,24$ \\
\hline Triglycerides $(\mathrm{mM})$ & $0,87 \pm 0,09$ & $0,81 \pm 0,07$ & $0,83 \pm 0,07$ \\
\hline Total cholesterol $(\mathrm{mM})$ & $2,11 \pm 0,11$ & $2,17 \pm 0,17$ & $2,04 \pm 0,21$ \\
\hline HDL-cholesterol $(\mathrm{mM})$ & $1,32 \pm 0,10$ & $1,36 \pm 0,12$ & $1,41 \pm 0,13$ \\
\hline
\end{tabular}

been demonstrated to stimulate inducible NO synthase in PI3Kdependent manner in vascular smooth muscle cells, and to inhibit angiotensin II-induced vasoconstriction (31) and smooth muscle cell proliferation (32) through the mechanism involving PI3K, Akt and iNOS.

In conclusion, we demonstrated that hyperleptinemia induced by administration of exogenous leptin increases PI3K activity in the aortic media in EGFR and ErbB2-dependent manner. In addition, leptin activates ErB2 receptor in the vascular wall by stimulating its phosphorylation by EGFR. EGFR/ErbB2/ PI3K pathway may contribute to effects of leptin on smooth muscle cell contractility, growth and proliferation and may mediate, at least in part, the relationship between leptin and cardiovascular pathologies in the metabolic syndrome.

\section{Acknowledgements}

This study was supported by EU Project "The equipment of innovative laboratories doing research on new medicines used in the therapy of civilization and neoplastic diseases" within the Operational Program Development of Eastern Poland 2007 - 2013, Priority Axis I Modern Economy, Operations I.3 Innovation Promotion.

\section{References}

1. Oudit GY, Sun H, Kerfant BG, Crackower MA, Penninger JM, Backx PH. The role of phosphoinositide-3 kinase and PTEN in cardiovascular physiology and disease. J Mol Cell Cardiol 2004; 37: 449-471.

2. Morello F, Perino A, Hirsch E. Phosphoinositide 3-kinase signalling in the vascular system. Cardiovasc Res 2009; 82: 261-271.

3. Bełtowski J, Jamroz-Wiśniewska A. Role of epidermal growth factor receptor (EGFR) in the pathogenesis and treatment of arterial hypertension. Biomed Rev 2007; 18: $1-26$.

4. Kshatriya S, Reams GP, Spear RM, Freeman RH, Dietz JR, Villarreal D. Obesity hypertension: the emerging role of leptin in renal and cardiovascular dyshomeostasis. Curr Opin Nephrol Hypertens 2010; 19: 72-78.

5. Jamroz-Wiśniewska A, Wójcicka G, Łowicka E, Książek M, Bełtowski J. Transactivation of epidermal growth factor receptor in vascular and renal systems in rats with experimental hyperleptinemia: Role in leptin-induced hypertension. Biochem Pharmacol 2008; 75: 1623-1638.

6. Chao HH, Hong HJ, Liu JC, Lin JW, Chen YL, Chiu WT, Wu $\mathrm{CH}$, Shyu KG, Cheng TH. Leptin stimulates endothelin-1 expression via extracellular signal-regulated kinase by epidermal growth factor receptor transactivation in rat aortic smooth muscle cells. Eur J Pharmacol 2007; 573: 49-54.

7. Frühbeck G. Intracellular signalling pathways activated by leptin. Biochem J 2006; 393: 7-20.

8. Citri A, Skaria KB, Yarden Y. The deaf and the dumb: the biology of ErbB-2 and ErbB-3. Exp Cell Res 2003; 284: 54-65.

9. Fuller SJ, Sivarajah K, Sugden PH. ErbB receptors, their ligands, and the consequences of their activation and inhibition in the myocardium. J Mol Cell Cardiol 2008; 44: 831854.

10. Soma D, Kitayama J, Yamashita H, Miyato H, Ishikawa M, Nagawa $\mathrm{H}$. Leptin augments proliferation of breast cancer cells via transactivation of HER2. J Surg Res 2008; 149: 9-14.

11. Eisenberg A, Biener E, Charlier M, Krishnan RV, Djiane J, Herman B, Gertler A. Transactivation of erbB2 by short and long isoforms of leptin receptors. FEBS Lett 2004; 565: 139142. 
12. Mifune M, Ohtsu H, Suzuki H, Frank GD, Inagami T, Utsunomiya $\mathrm{H}$, et al. Signal transduction of betacellulin in growth and migration of vascular smooth muscle cells. Am J Physiol Cell Physiol 2004; 287: C807-813.

13. Jones RB, Gordus A, Krall JA, MacBeath G. A quantitative protein interaction network for the ErbB receptors using protein microarrays. Nature 2006; 439: 168-174.

14. Seki T, Yokoshiki H, Sunagawa M, Nakamura M, Sperelakis N. Angiotensin II stimulation of $\mathrm{Ca}^{2+}$-channel current in vascular smooth muscle cells is inhibited by lavendustin-A and LY-294002. Pflugers Arch 1999; 437: 317-323.

15. Viard P, Exner T, Maier U, Mironneau J, Nurnberg B, Macrez N. G $\beta \gamma$ dimers stimulate vascular L-type $\mathrm{Ca}^{2+}$ channels via phosphoinositide 3-kinase. FASEB J 1999; 13: 685-694.

16. Quignard JF, Mironneau J, Carricaburu V, Fournier B, Babich A, Nurnberg B, et al. Phosphoinositide 3-kinase $\gamma$ mediates angiotensin II-induced stimulation of L-type calcium channels in vascular myocytes. J Biol Chem 2001; 276: 32545-32551.

17. Zubkov AY, Rollins KS, Parent AD, Zhang J, Bryan RM. Mechanism of endothelin-1-induced contraction in rabbit basilar artery. Stroke 2000; 31: 526-533.

18. Kawanabe Y, Hashimoto N, Masaki T. Effects of phosphoinositide 3-kinase on endothelin-1-induced activation of voltage-independent $\mathrm{Ca}^{2+}$ channels and vasoconstriction. Biochem Pharmacol 2004; 68: 215-221.

19. Northcott CA, Hayflick JS, Watts SW. PI3-kinase upregulation and involvement in spontaneous tone in arteries from DOCA-salt rats: is p110 $\delta$ the culprit? Hypertension 2004; 43 : 885-890.

20. Seok YM, Azam MA, Okamoto Y, Sato A, Yoshioka K, Maeda $\mathrm{M}$, et al. Enhanced $\mathrm{Ca}^{2+}$-dependent activation of phosphoinositide 3-kinase class IIa isoform-Rho axis in blood vessels of spontaneously hypertensive rats. Hypertension 2010; 56: 934-941.

21. Vecchione C, Patrucco E, Marino G, Barberis L, Poulet R, Aretini A, et al. Protection from angiotensin II-mediated vasculotoxic and hypertensive response in mice lacking PI3K . J Exp Med 2005; 201: 1217-1228.

22. Carnevale D, Vecchione C, Mascio G, Esposito G, Cifelli G, Martinello $\mathrm{K}$, et al. $\mathrm{PI} 3 \mathrm{~K} \gamma$ inhibition reduces blood pressure by a vasorelaxant Akt/L-type calcium channel mechanism. Cardiovasc Res 2012; 93: 200-209.

23. Fougerat A, Gayral S, Gourdy P, Schambourg A, Rückle T, Schwarz MK, et al. Genetic and pharmacological targeting of phosphoinositide 3-kinase- $\gamma$ reduces atherosclerosis and favors plaque stability by modulating inflammatory processes. Circulation 2008; 117: 1310-1317.

24. Furgeson SB, Simpson PA, Park I, Vanputten V, Horita H, Kontos CD, et al. Inactivation of the tumour suppressor, PTEN, in smooth muscle promotes a pro-inflammatory phenotype and enhances neointima formation. Cardiovasc Res 2010; 86: 274-282.

25. Choi KH, Kim JE, Song NR, Son JE, Hwang MK, Byun S, et al. Phosphoinositide 3-kinase is a novel target of piceatannol for inhibiting PDGF-BB-induced proliferation and migration in human aortic smooth muscle cells. Cardiovasc Res 2010; 85: 836-844.

26. Shan J, Nguyen TB, Totary-Jain H, Dansky H, Marx SO, Marks AR. Leptin-enhanced neointimal hyperplasia is reduced by mTOR and PI3K inhibitors. Proc Natl Acad Sci USA 2008; 105: 19006-19011.

27. Stephenson K, Tunstead J, Tsai A, Gordon R, Henderson S, Dansky HM. Neointimal formation after endovascular arterial injury is markedly attenuated in $\mathrm{db} / \mathrm{db}$ mice. Arterioscler Thromb Vasc Biol 2003; 23: 2027-2033.

28. Bodary PF, Shen Y, Ohman M, Bahrou KL, Vargas FB, Cudney SS, et al. Leptin regulates neointima formation after arterial injury through mechanisms independent of blood pressure and the leptin receptor/STAT3 signaling pathways involved in energy balance. Arterioscler Thromb Vasc Biol 2007; 27: 70-76.

29. Piatti P, Di Mario C, Monti LD, Fragasso G, Sgura F, Caumo A, et al. Association of insulin resistance, hyperleptinemia, and impaired nitric oxide release with in-stent restenosis in patients undergoing coronary stenting. Circulation 2003; 108: 2074-2081.

30. Galluccio E, Piatti P, Citterio L, Lucotti PC, Setola E, Cassina $\mathrm{L}$, et al. Hyperinsulinemia and impaired leptin-adiponectin ratio associate with endothelial nitric oxide synthase polymorphisms in subjects with in-stent restenosis. Am J Physiol Endocrinol Metab 2008; 294: E978-986.

31. Rodríguez A, Fortuño A, Gómez-Ambrosi J, Zalba G, Díez J, Frühbeck G. The inhibitory effect of leptin on angiotensin II-induced vasoconstriction in vascular smooth muscle cells is mediated via a nitric oxide-dependent mechanism. Endocrinology 2007; 148: 324-331.

32. Rodríguez A, Gómez-Ambrosi J, Catalán V, Fortuño A, Frühbeck G. Leptin inhibits the proliferation of vascular smooth muscle cells induced by angiotensin II through nitric oxide-dependent mechanisms. Mediators Inflamm 2010; 2010: 105489. 